\title{
Intrathoracic rupture of hydatid cyst of the liver in children: a report of two cases
}

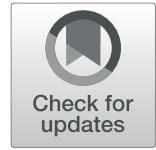

Rachida Laamiri ${ }^{*}$ (D, Sahla Sellami ${ }^{1}$, Nahla Kechiche ${ }^{1}$, Mabrouk Abdelaali ${ }^{2}$, Mongi Mekki and Mohsen Belghith ${ }^{1}$

\begin{abstract}
Background: Intrathoracic rupture of hepatic hydatid cyst is a rare but dangerous complication. Its occurrence in children is exceptional as diagnosis and management constitute real challenges. We report two cases of intrathoracic rupture of hepatic hydatid cyst in children.

Case presentation: Our patients were respectively 12-year-old boy and 9-year-old girl, known cases of respiratory symptoms, diagnosed initially for pleuropneumonia. The CT scan established the diagnosis of intrathoracic rupture of hepatic hydatid cyst in the pleural cavity for the first patient and in the bronchial tree for the second. An emergency surgery was performed for both. The second patient developed broncho-biliary fistulas during the postoperative course which necessitated a re-intervention. A recurrence was noted at follow-up for the second patient.

Conclusion: Intrathoracic rupture of hepatic hydatid cyst is a serious complication which can occur even in children. Its diagnosis needs a high index of suspicion. The surgical approach remains controversial and there is a lack of consensus about the best way of management. Recurrence may occur despite appropriate treatment.
\end{abstract}

Keywords: Intrathoracic rupture, Hepatic hydatid cyst, Children, Diagnosis, Management

\section{Background}

The hydatid disease is an endemic parasitic pathology in the Mediterranean countries including Tunisia that can be observed at any age [1]. The most commonly affected organ in children is the lung at first followed by liver $[1,2]$. Some complicated forms can cause morbidity and mortality. Intrathoracic rupture is a rare but dangerous complication that may occur even in children with challenges in terms of diagnosis and treatment [3].

We are presenting two cases of intrathoracic rupture in children and discussing the diagnosis and management of this complication.

\section{Case presentation}

\section{Case 1}

A 12-year-old boy presented to the Paediatrics Emergency Care for dyspnea, right side chest pain, and fever of

\footnotetext{
* Correspondence: lamiri.rachida@yahoo.fr

${ }^{1}$ Pediatric Surgery Department, University Hospital, University of Monastir, Monastir, Tunisia

Full list of author information is available at the end of the article
}

around 7 days of evolution. The physical examination revealed fever, bronchial rales, and no breath sounds on the right lung base. The chest X-ray showed moderate right-sided pleural effusion. The diagnosis of a right pleuropneumonia was initially retained and treated with antibiotics: vancomycin and cefotaxime initially for 4 days with no improvement. A thoracoabdominal CT scan was then performed showing a collapsed hydatid cyst of the hepatic dome, a detached laminated membrane in the pleural cavity (Fig. 1) with a collapse of the inferior side of the right lung, and a 3-cm breach in the right diaphragm. An emergency laparotomy via right subcostal approach was performed revealing (Fig. 2) a hydatid cyst with a tear of the superior surface on the hepatic dome without biliary fistula, a $3-\mathrm{cm}$ large diaphragmatic breach through which seropurulent fluid, daughter vesicles, and germinative membrane disseminated to pleural cavity. Phrenopulmonary and hepato-diaphragmatic disconnection were performed. The pleural cavity was irrigated with hypertonic saline through the breach with the evacuation of the membrane. Diaphragmatic closure was achieved and a
SpringerOpen (c) The Author(s). 2021 Open Access This article is licensed under a Creative Commons Attribution 4.0 International License, which permits use, sharing, adaptation, distribution and reproduction in any medium or format, as long as you give appropriate credit to the original author(s) and the source, provide a link to the Creative Commons licence, and indicate if changes were made. The images or other third party material in this article are included in the article's Creative Commons licence, unless indicated otherwise in a credit line to the material. If material is not included in the article's Creative Commons licence and your intended use is not permitted by statutory regulation or exceeds the permitted use, you will need to obtain permission directly from the copyright holder. To view a copy of this licence, visit http://creativecommons.org/licenses/by/4.0/. 


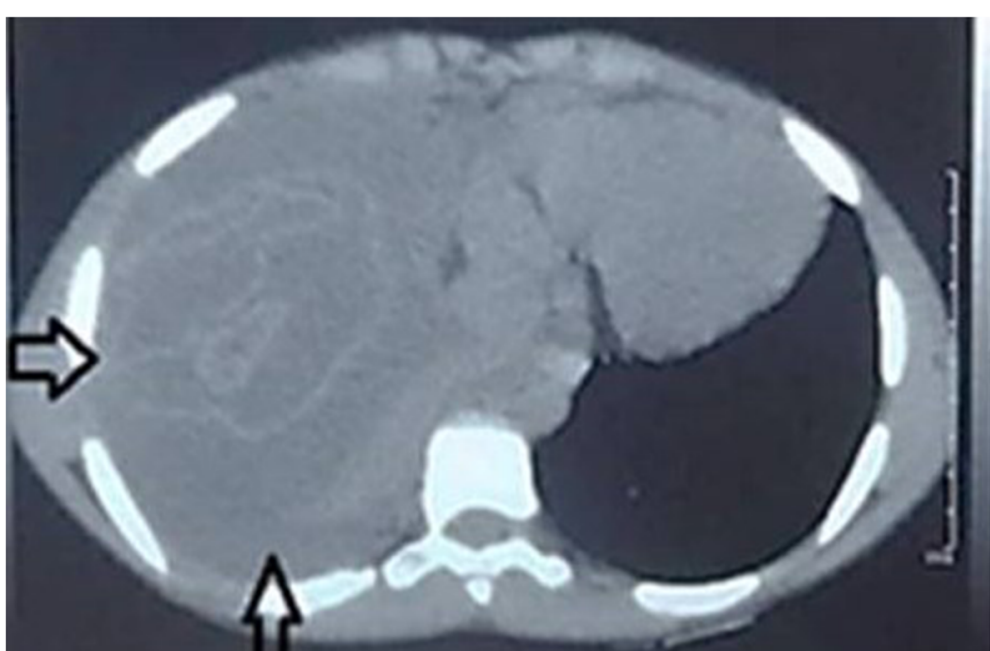

Fig. $1 \mathrm{CT}$ scan showing a detached laminated membrane in the pleural cavity

chest tube was inserted. Albendazole therapy was administered for 6 months after an uneventful post-operative course. No recurrence or other hydatid localizations were detected after 2 years of follow-up.

\section{Case 2}

A 9-year-old girl presented to Pediatric Emergency Care for cough, hemoptysis, and chest pain of around 10 days of evolution. On examination, her temperature was 38.6 ${ }^{\circ} \mathrm{C}$, auscultation found bronchial rales and decreased breath sound on the right lung base, and abdominal examination revealed right abdominal tenderness. Chest X-ray showed right-sided pleural effusion suggesting pleuropneumonia treated with antibiotics: penicillin and gentamicin initially with no improvement of clinical and paraclinical features after 5 days. Therefore, a thoracoabdominal CT scan was performed revealing a hydatid cyst of the hepatic dome complicated by intrathoracic rupture into the bronchial tree (Fig. 3). The patient underwent an emergency surgery via right subcostal approach. After performing diaphragmatic disconnection, exploration revealed a collapsed liver hydatid cyst and a

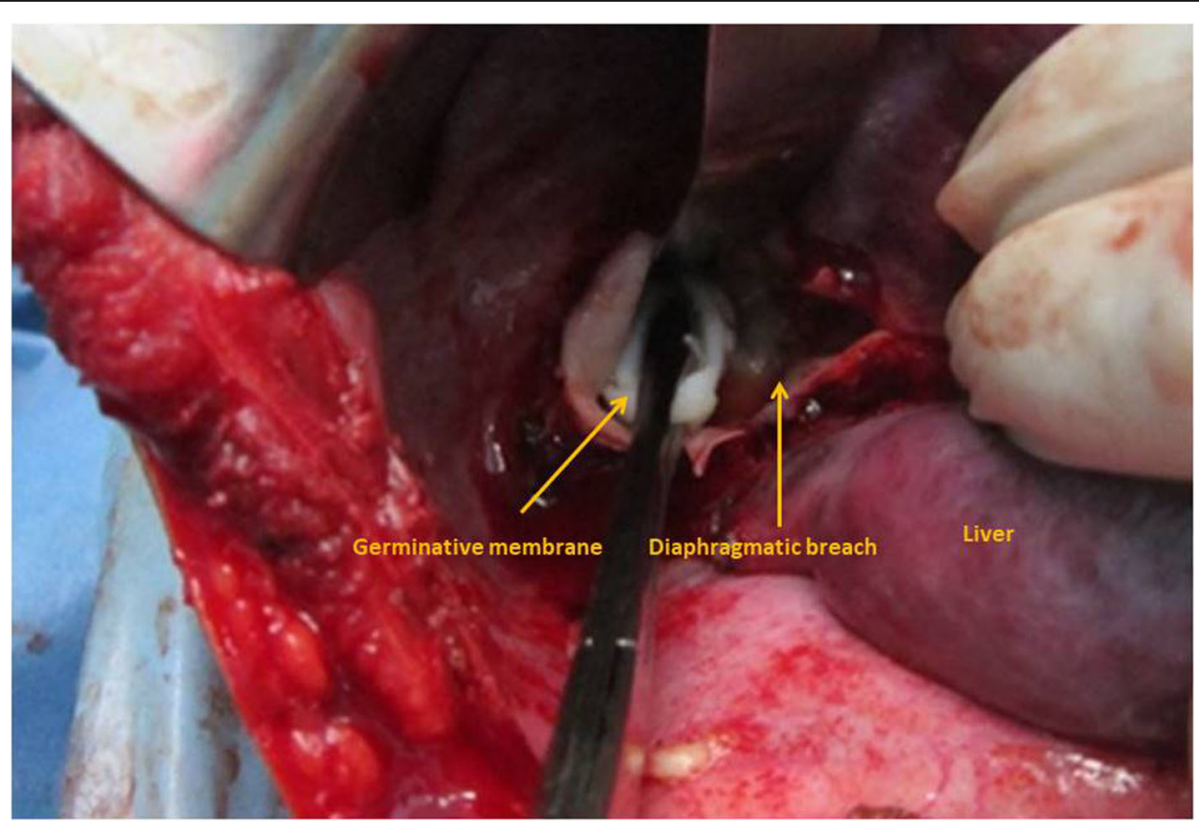

Fig. 2 Surgical specimen revealing an hydatid cyst on the hepatic dome and a 3-cm large diaphragmatic breach through which germinative membrane disseminated to pleural cavity 


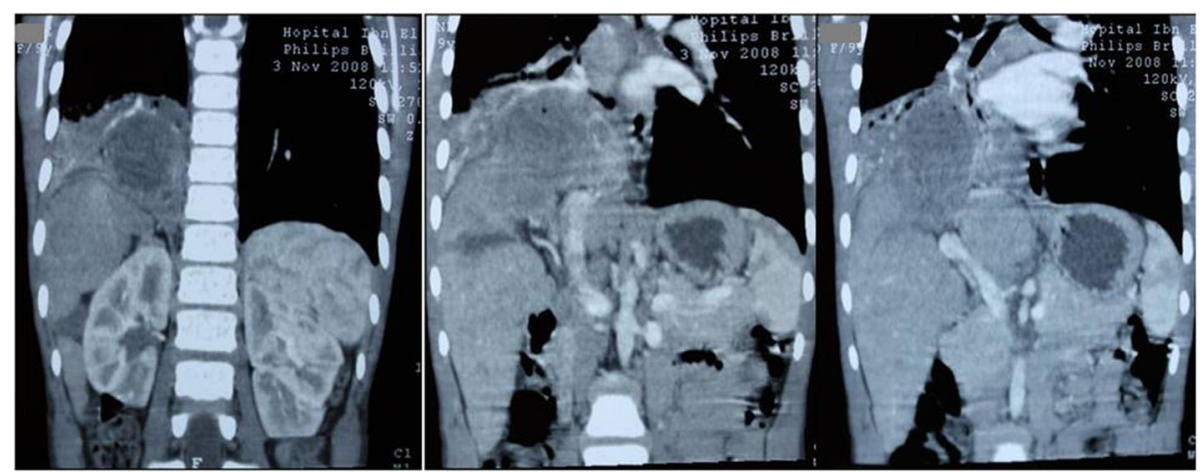

Fig. 3 CT scan revealing a hydatid cyst of the hepatic dome complicated by intrathoracic rupture into the bronchial tree

diaphragmatic breach of $5 \mathrm{~cm}$ through which the germinative membrane disseminated to the lung, an excision of the membrane was performed through the breach. The treatment of pulmonary lesions was impossible via abdominal approach; therefore, posterolateral thoracotomy in the sixth intercostal space was performed allowing closure of bronchial fistulas and the diaphragmatic breach; a chest tube and abdominal drain were inserted. Postoperative day (POD) 3, our patient presented biliptysis. A thoraco-abdominal CT scan was realized the next day and revealed a diaphragmatic breach with bronchobilary fistula; the patient was then re-operated via subcostal approach. A minimally biliary fistula was found, diaphragmatic closure was achieved before insertion of the drainage tube into the cystic duct. No complication appeared in evolution, and our patient was discharged 19 days after second surgery. Albendazole therapy was administered for 6 months. After 2 years of follow-up, she presented pleural hydatid cyst recurrence of $2.4 \mathrm{~cm}$ treated successfully with albendazole.

\section{Discussion}

Intrathoracic rupture of hepatic hydatid cyst is a rare clinical pathology with a reported frequency of 0.6 to $1.6 \%$ in adult population [4]. The rupture into the pleural cavity is less common than in the bronchial tree [5]. Several factors explain this complication: the negative intrathoracic pressure which tends to aspirate the hepatic hydatid cyst, the mechanical compression exerted by the cyst on the diaphragm leading to muscles erosion, the infection of the cyst leading to muscle necrosis, and in the case of biliary fistulas, the caustic feature of the bile caused a chemical erosion of the diaphragm, lung, and pleura [6]. This complication results from the long evolution of a hydatid cyst of the hepatic dome and generally reported in young adults [3, 7]. Caustic action on the lung or bronchial tree caused by the bile will damage the pulmonary parenchyma with lesions ranging from simple hydatid pneumonia to the constitution of a cave. Once the cyst gets through the diaphragm, different lesional aspects may result, classified according to Mestiri et al. into 4 types and 9 subtypes [8]. Referring to this classification, our patients are classified respectively as type IVb and Ib.

Intrathoracic rupture is usually revealed through respiratory and thoracic symptoms. Hydatic vomica and pathognomonic hydatidoptysis of hydatid disease are less commonly reported [3].

Chest X-ray is not very helpful. It shows a right lower lobe opacity or pleural effusion. An ultrasound exam is essential for some authors as it shows the hepatic hydatid cyst and its close connection with thoracic lesions, visualizes the diaphragmatic discontinuity, highlights thoracic lesions, and explores the biliary tract [3]. However, CT scan is more effective than ultrasound in assessing pulmonary pleural and parenchymal lesions [3]. In our patients, the chest X-ray showed right sided pleural effusion. The lack of clinical improvement leads us to suspect lung hydatid cyst rupture in the pleural cavity as our patients come from an endemic echinococcosis area. We completed this by CT scan to establish our diagnosis.

The surgical approach to treat hepatic hydatid cyst with thoracic involvement is controversial [3, 4, 9]. Surgery can be performed by thoracotomy only, thoracophrenolaparotomy, laparotomy only, or associated with thoracotomy [7]. The abdominal approach enables to treat the liver cyst, to evacuate the pleural cavity through the diaphragmatic breccia and to restore the diaphragm [9]. The treatment of pleuropulmonary lesions have been reported to represent the limitation of this approach in adult because the important lesions of the pulmonary parenchyma required a regulated resection such as lobectomy or segmentectomy $[3,7]$. The thoracic approach offering adequate access to treat both thoracic and abdominal lesions is defended by some authors $[4,5,10,11]$.

In pediatrics population, surgery must be conservative and most of pulmonary lesions caused by hepatic hydatid rupture are minimal and located on the lower or 
middle pulmonary lobe $[5,7]$. That is why we prefer abdominal approach only to treat hepatic hydatid cyst with thoracic involvement. For our first patient, given the absence of significant pleuro-pulmonary lesions, the abdominal approach proved to be effective and safe. For the second patient bronchial fistulas treatment was impossible by the laparotomy which required additional thoracic approach.

Medical adjuvant treatment is indicated when hydatid disease dissemination and total cysts resection is not possible. Albendazole $(10 \mathrm{mg} / \mathrm{kg} /$ day given b.i.d) for 6 months is the current recommended therapy when indicated. Prophylactic measures should always be taken in endemic areas [11].

Despite diagnosis and therapeutic progress, this complication has high mortality and recurrence rate $(7.5 \% ; 16 \%)[3-5]$.

\section{Conclusion}

Intrathoracic rupture of hepatic hydatid cyst is a rare but a serious complication which can occur even in children. The treatment is essentially surgical; the approach is controversial and depends on the anatomic type of lesion. The prevention from this complication involves early diagnosis and primary prevention of hydatid disease.

\section{Acknowledgements}

Not applicable

\section{Authors' contributions}

RL: has drafted the work, SS: traduction (English), NK: traduction (English), AM: analyzes radiologic exams, MM: has substantively revised the work, MB: has substantively revised the work. All the authors have read and approved the manuscript.

\section{Funding}

No source

Availability of data and materials

Not applicable

\section{Declarations}

\section{Ethics approval and consent to participate}

We had the agreement of the ethics committee of our medical school of Monastir.

\section{Consent for publication}

Written informed consent to publish this information was obtained from the parent and/or legal guardian and will be sent when requested at any time by editorial teams with the consent for publication from study participants. As the authors, we hereby grant and assign to Egyptian liver journal all rights in and acknowledge that Egyptian liver journal will have the right to publish the work.

\section{Competing interests}

The authors declare that they have no competing interests.

\section{Author details}

${ }^{1}$ Pediatric Surgery Department, University Hospital, University of Monastir, Monastir, Tunisia. Imagery Department, University Hospital, University of Monastir, Monastir, Tunisia.
Received: 7 January 2021 Accepted: 26 May 2021

Published online: 08 June 2021

References

1. M'rad S, Oudni-M'rad M, Boubaker G, Bouazzi L, Gorcii M, Nouri A et al (2012) Étude rétrospective de la distribution et de la fertilité des kystes hydatiques chez l'enfant en Tunisie. Pathol Biol (Paris) Jun 60(3):166-169. https://doi.org/10.1016/j.patbio.2011.03.002

2. Eyüboğlu TŞ, Gürsoy TR, Aslan AT, Pekcan S, Budakoğlu II (2019) Ten-year follow-up of children with hydatid cysts. Turk Pediatri Ars 54(3):173-178. https://doi.org/10.14744/TurkPediatriArs.2019.24119

3. Kilani T, El Hammami S, Horchani H, Ben Miled-Mrad K, Hantous S, Mestiri I et al (2001) Hydatid disease of the liver with thoracic involvement. World J Surg 1:40-45

4. Belliraj L, Alzouma II, Ammor FZ, Harmouchi H, Rabiou S, Lakrambi M et al (2017) La prise en charge des kystes hydatiques du foie (KHF) rompus dans le thorax à propos de 31 cas. Rev Mal Respir 34(Suppl):A99

5. Msougar Y, Lakranbi M, Bouchikh M, Ouadnouni Y, Maidi M, Fenan $\mathrm{H}$ et al (2010) La place de la thoracotomie dans le traitement des kystes hydatiques abdominaux rompus dans le thorax. Rev Mal Respir 5:417-420

6. Kilani T, Daoues A, Horchani H, Sellami M (1991) Place de la thoracotomie dans les complications thoraciques des kystes hydatiques du foie. Ann. Chir Thorac Cardiovasc 45:705

7. Rabiou S, Harmouchi H, Belliraj L, Ammor FZ, Issoufou I, Sidibé K et al (2017) Management for ruptured liver hydatid cysts in the chest: experience of a Moroccan center. Clin Surg 2:1757

8. Mestiri S, Kilani T, Thameur H, Sassi S (1987) Thoracic migrations of hydatid cysts of the liver : proposal for a classification. Lyon Chir 1:12-16

9. Sakhri J, Benali A, Letaief R, Derbel F, Dahmen Y, Ben Hadj Hmida R (1996) Les kystes hydatiques du foie rompus dans le thorax : aspects diagnostiques et thérapeutiques. J Chir 133(9-10):437-441

10. Rabiou S, Lakranbi M, Ouadnouni Y, Panaro F, Smahi M (2017) Surgical management of hydatid Bilio-bronchial fistula by exclusive thoracotomy. Int J Surg 41:112-118. https://doi.org/10.1016/j.jisu.2017.03.074

11. Kabiri H, El Maslout A, Benosman A (2001) Thoracic rupture of hepatic hydatidosis (123 cases). Ann Thorac Surg 72(6):1883-1886. https://doi.org/1 0.1016/50003-4975(01)03204-0

\section{Publisher's Note}

Springer Nature remains neutral with regard to jurisdictional claims in published maps and institutional affiliations.

\section{Submit your manuscript to a SpringerOpen ${ }^{\circ}$ journal and benefit from:}

- Convenient online submission

- Rigorous peer review

- Open access: articles freely available online

High visibility within the field

- Retaining the copyright to your article

Submit your next manuscript at $\boldsymbol{\nabla}$ springeropen.com 